S7 File. Clinical psychological science results

\title{
Clinical Psychological Science
}

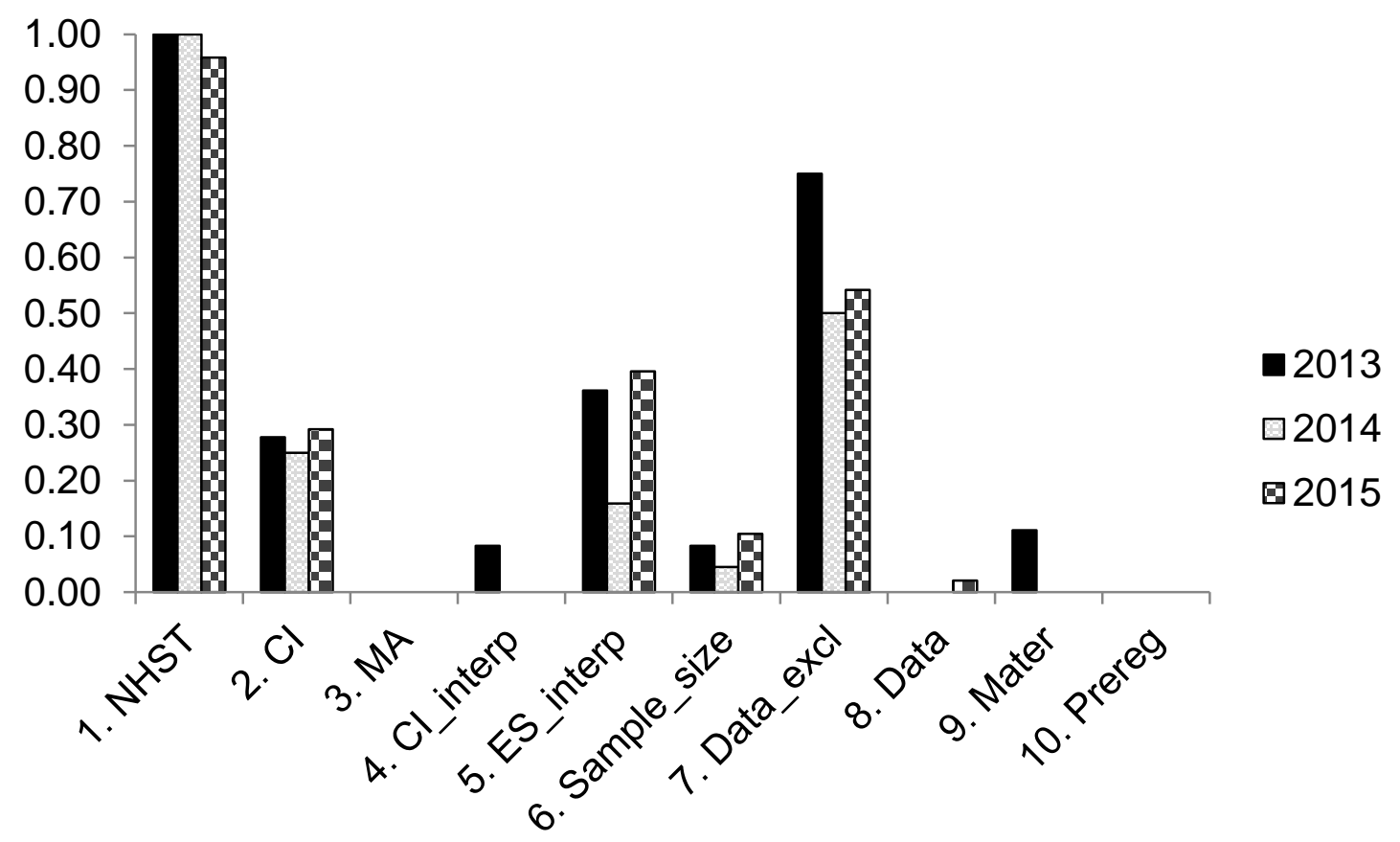

Figure 1S. Proportions of papers with at least one occurrence of various practices, in Clinical Psychological Science, for each of three years, see text for definitions of labels on the horizontal axis. Number of papers included: $2013(n=36), 2014(n=44), 2015(n=48)$.

\section{Clinical Psychological Science}

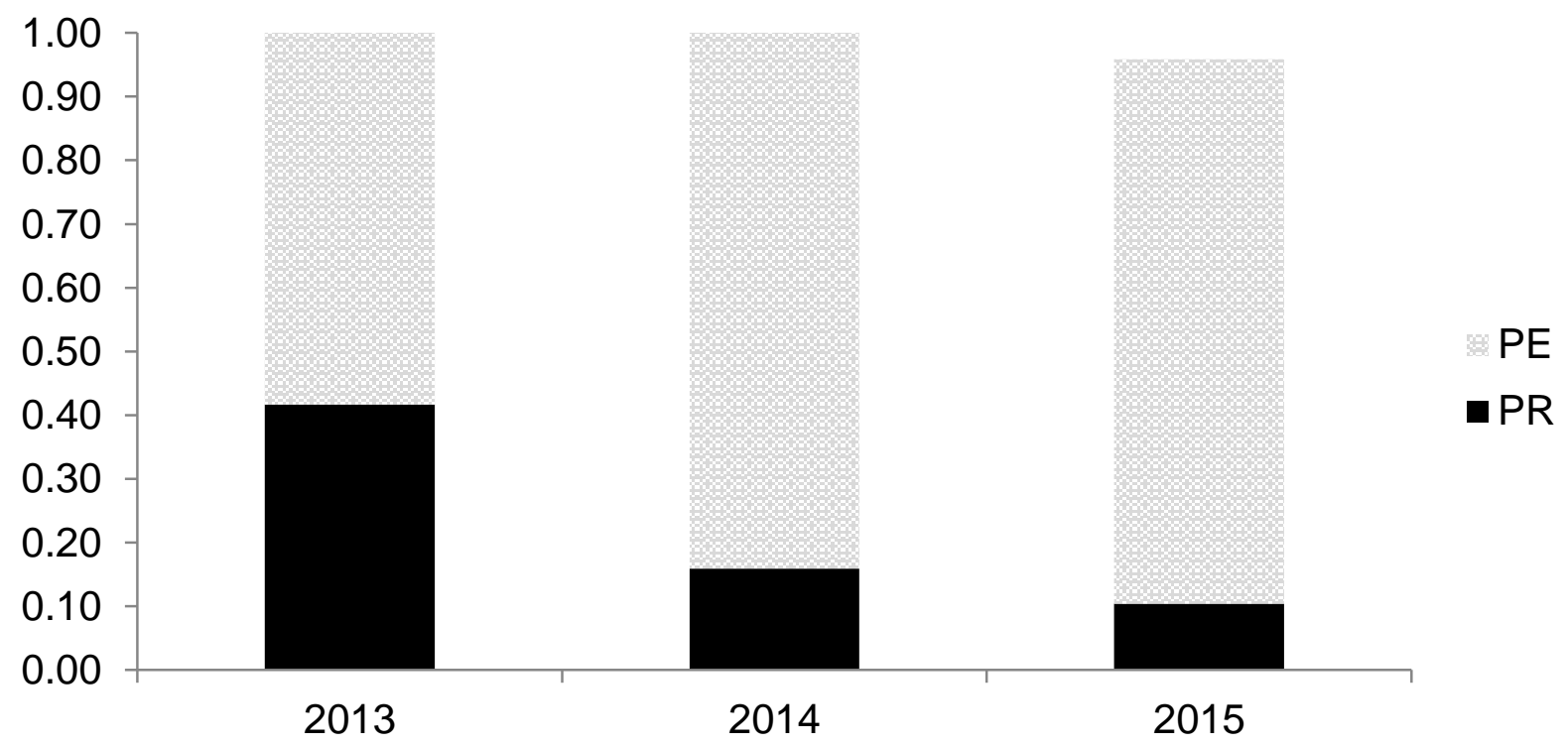

Figure 2S. Proportions of papers with PR ( $p$ relative) or PE ( $p$ exact), in Clinical Psychological Science for each of three years. 